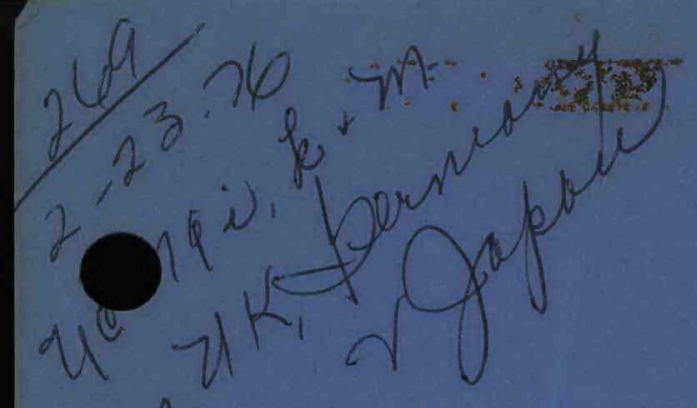

Or -2046

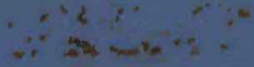

HEDL-TME 75-133

UC-79i, k, m

\title{
FEASIBILITY STUDY ON
}

INFRARED ELECTRO-THERMAL

NDE OF STAINLESS STEEL 


\section{DISCLAIMER}

This report was prepared as an account of work sponsored by an agency of the United States Government. Neither the United States Government nor any agency Thereof, nor any of their employees, makes any warranty, express or implied, or assumes any legal liability or responsibility for the accuracy, completeness, or usefulness of any information, apparatus, product, or process disclosed, or represents that its use would not infringe privately owned rights. Reference herein to any specific commercial product, process, or service by trade name, trademark, manufacturer, or otherwise does not necessarily constitute or imply its endorsement, recommendation, or favoring by the United States Government or any agency thereof. The views and opinions of authors expressed herein do not necessarily state or reflect those of the United States Government or any agency thereof. 


\section{DISCLAIMER}

Portions of this document may be illegible in electronic image products. Images are produced from the best available original document. 

HEDL-TME 75-133

$U C-79 i, k, m$

FEASIBILITY STUDY ON

INFRARED ELECTRO-THERMAL

NDE OF STAINLESS STEEL

D. R. Green and J. A. Hassberger

November, 1975

Tha report was prepered as an account of work sponsored by the United States Government Nenther the United States nor the Unuted States Energy Research and Development Admurustration, nor any of therr employes, nor any of their contractors, subcontractors, or thetr employecs, makes any labulty or responsubulty for the accuracy, completeness or usefulness of any informa tion, apparatus, product of

process disclosed, or represents that its use would not
infinnge privitely owned rights

\section{Hanford Engineering Development Laboratory}

Operated by the

Westinghouse

Hanford Company
A Subsidiary of

Westinghouse Electric

Corporation for the United Stetes

Energy Resea reh and

Development Administration Contract No E(45-1)2170 
•

• 
HEDL-TME 75-133

$U C-79 i, k, m$

\title{
FEASIBILITY STUDY ON INFRARED ELECTRO-
}

THERMAL NDE OF STAINLESS STEEL

\author{
D. R. Green
}

J. A. Hassberger

ABSTRACT

Electro-thermal examination, a branch of thermal testing (TT), is a promising method being developed for NDE of stainless steel welds. This report describes the first phase of devetopment; i.e., preliminary demonstration and laboratory evaluation of the method's sensitivity to notches in Type 304 stainless steel plate specimens. It also includes a description of the basic principles, together with a description of the hardware and experimental results showin that electrical discharge machined notches down to $0.16 \mathrm{~cm}(0.06 \mathrm{in}$.) long $x 0.08 \mathrm{~cm}(0.03 \mathrm{in}$.) deep were detected. A qualitative technique for interpreting the test results to determine whether defeats are at the surface or deeper within the material is demonstrated. 
TABLE OF CONTENTS

Page

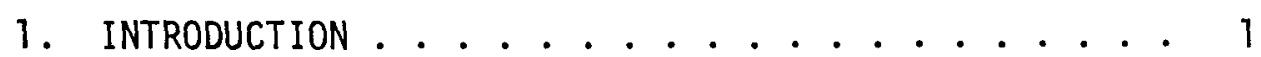

2. SUMMARY AND CONCLUSIONS . . . . . . . . 2

3. BASIC PRINCIPLES AND THEORY OF OPERATION . . . . . 3

4. EXPERIMENTAL APPARATUS ............ 6

5. TEST SPECIMENS .................... 9

6. EXPERIMENTAL PROCEDURE AND RESULTS . . . . . . 11

7. ACKNOWLEDGMENTS ............... 20

8. REFERENCE ................... 20

APPENDIX A - TEMPERATURE VERSUS TIME AROUND AN A-1 INSTANTANEOUS POINT HEAT SOURCE 


\section{LIST OF FIGURES}

Figure

Page

1. Electric Current Flow and Surface Heating Near a

Subsurface Flaw ................ 4

2. Electric Current and Surface Heating Near a Surface Flaw ... 5

3. Experimental Electro-Thermal System for Stainless Steel

Plate Specimens .............. 7

4. Stainless Steel Plate Specimen and Output Contact Bars

of the Electro-Thermal System ........... 8

5. Stainless Steel Plate Specimen Containing Electric

Discharge Machined Notch ............ 10

6. Three Experimental Arrangements Used in the

Sensitivity Evaluations ............. . 12

7. Electro-Thermal Indications of $0.013 \mathrm{~cm}(0.005 \mathrm{in.})$

wide Notches in $0.5 \mathrm{~cm}(0.2$ in.) thick $\times 5 \mathrm{~cm}(2 \mathrm{in.})$

wide Stainless Steel Plate............. 15

8. Electro-Thermal Indications of $0.013 \mathrm{~cm}(0.005 \mathrm{in.})$

wide Notches in the Near Side of Flat Black Coated

Stainless Steel Plates $0.5 \mathrm{~cm}(0.2$ in.) thick $x$

$5 \mathrm{~cm}$ ( 2 in.) wide. Electric Current Applied

Symmetricaliy ................. . . 17

9. Electro-Thermal Indications of $0.013 \mathrm{~cm}(0.005 \mathrm{in.})$

wide Notches in the Far Side of $0.5 \mathrm{~cm}(0.02$ in.)

thick $\times 5 \mathrm{~cm}$ (2 in.) wide Stainless Steel Plates.

Electric Current Applied Symmetrically.......... 18 


\section{LIST OF TABLES}

Table $\quad \underline{\text { Page }}$

I Notch Sizes.................... 11

II Sensitivity to Near-Side Surface Defects in Specimens with Symmetric Current Application . . . . . . . . . . 14

III Sensitivity to Near-Side Defects in Flat Black Coated Specimens with Symmetric Current Application . . . . . . . . 16

IV Sensitivity to Far-Side Surface Defects in Specimens with Symmetric Current Application . . . . . . . . . . 19

$V \quad$ Sensitivity to Far-Side Surface Defects in Specimens with Near-Side Current Application . . . . . . . . . 20 


\section{INTRODUCTION}

Development of improved nondestructive examination methods for stainless steel is an important objective in the nuclear industry. Electro-thermal nondestructive examination (ETE), which is performed by passing a short, highamplitude electrical current pulse through a test object and mapping the resulting surface temperatures, is affected by a different set of material characteristics than the more common nondestructive examination methods. Hence, ETE is a possible alternative for detecting flaws in stainless steel welds where microstructural variations may decrease the effectiveness of eddy current (ET) and ultrasonic (UT) examination. In addition, ETE has potential for in-service inspection of nuclear reactor components, since the thermal mapping instrument can be shielded from nuclear radiation.

This report describes work done under Energy Research and Development Administration 189a FF029/GTJ on the first phase of development; i.e., a pre1 iminary demonstration and laboratory experimental evaluation of the electrothermal examination method's sensitivity to notches in smooth-surfaced stainless steel test plates. Evaluation of the electro-thermal method on test specimens having wavy surfaces, such as welds, was beyond the scope of this phase since it will require a high frequency, high current source to 1 imit the penetration depth and minimize the effects of surface waviness. Although limited in scope, the work described here gave a clear indication of the potential sensitivity in stainless steel. The electro-thermal method has at least one problem in common with the ultrasonic and eddy current methods; it will not detect flaws having internal walls in tight contact. However, as with UT and ET, if the walls are separated by even a minute distance, the electro-thermal method is sensitive to thin planar defects, such as cracks and lack of fusion, that can be missed by radiographic examination. Rounded defects can also be detected using ETE, since they have an effect similar to that of planar defects. 


\section{SUMMARY AND CONCLUSIONS}

The electro-thermal method was demonstrated to be useful for detection of flaws in flat plates made of Type 304 stainless steel. Even the crude experimental system assembled for this evaluation was capable of detecting flaws having penetrations down to 16 percent of the wall thickness in both the inside and outside surfaces of stainless steel walls up to $0.5 \mathrm{~cm}(0.2 \mathrm{in.})$ thick. Interpretation of the results, and determination of whether flaws intersect the outside surface or are deeper within the test specimen, appears relatively straightforward.

Many improvements over the initial experimental system are possible. Current limitations resulting from non-uniform contact between the specimen and contact bars in the system can be relieved by developing better contacts. Such development was beyond the scope of the present brief study which was intended only to demonstrate and evaluate the method, and establish design criteria for an electro-thermal system. Flexible contacts will have to be developed for a field usable system since the test objects would be neither flat nor uniform. Shaping the contact area to concentrate the current should improve the sensitivity for small defects on the outside surface. The experimental results obtained during the first phase effort using flat plate specimens were sufficiently successful to justify proceeding with the second phase of the work, i.e., development of improved electrical contacts and a system suitable for experimental nondestructive examination of stainless steel pipe welds. Although most of the present experiments were conducted with uncoated specimens, there was an improvement in sensitivity when a flat black coating was applied to increase the emittance and make it more uniform. Development of a technique eliminating emittance effects without using a coating would be desirable.

The electro-thermal system can be made portable, requiring about the same arrangement as a large portable magnetic particle examination system. Although the instantaneous power requirement is high, the duration of each test is only $0.1 \mathrm{sec}$. 
Electro-thermal nondestructive examination (ETE) could fulfill a role in austenitic stainless steel similar to that fulfilled by magnetic particle examination (MT) is ferritic materials. Although the sensitivity of ETE to surface defects in stainless steel is not as great as that of MT in carbon steel, it appears to have greater sensitivity to subsurface defects. Evaluation of the initial experimental ETE system was promising, and further development is required to exploit the full potential of the method.

\section{BASIC PRINCIPLES AND THEORY OF OPERATION}

Low frequency electric current flowing through a uniform conductor is uniformly distributed. Any nonconductive region in the conductor, such as a crack or other flaw, causes the current in its vicinity to abruptly assume a new direction and amplitude distribution. Electrical current at a large distance (relative to flaw size) from the flaw is essentially undisturbed by the flaw's presence. The initial rate of temperature increase in each elemental volume of the test specimen depends upon the square of the electrical current density in that region. Hence, when a volumetric flaw (one that is located anywhere in the volume of the specimen but not intersecting the surface) is present, a warmer region is produced at the surface over the flaw because of the higher current density there, as shown in Figure 1. A surface flaw, on the other hand, produces a different surface current density and temperature distribution, as shown in Figure 2. The current distribution around a surface flaw results in cooler spots upstream and downstream, and warmer spots on each end of the flaw. Assuming constant geometry, increasing the projection of flaw area perpendicular to the current flow increases the sensitivity. This means that current flow should be as nearly perpendicular to planar flaws as possible. Bi-directional testing similar to the procedure used in magnetic particle testing would be advantageous in practical ETE applications.

Analytical computation of the three-dimensional time-transient temperatures generated by nonuniform electrical currents around a flaw during electrothermal examination is beyond the state-of-the-art. Computer determination of the surface temperatures expected to result from various combinations of electrical current density and flaw geometry, size, and location was considered. 


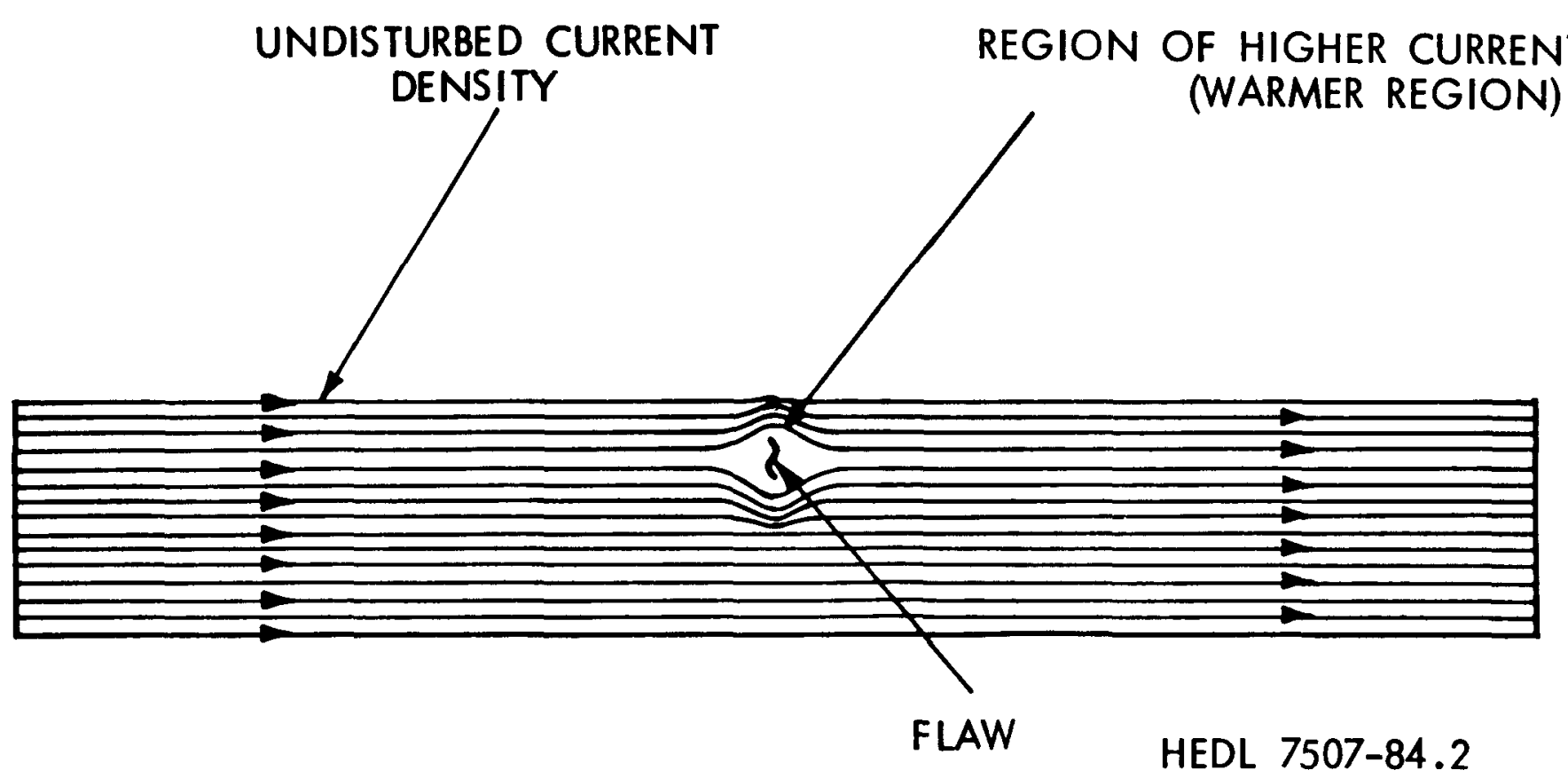

FIGURE 1. Electric Current Flow and Surface Heating Near a Subsurface Flaw. 


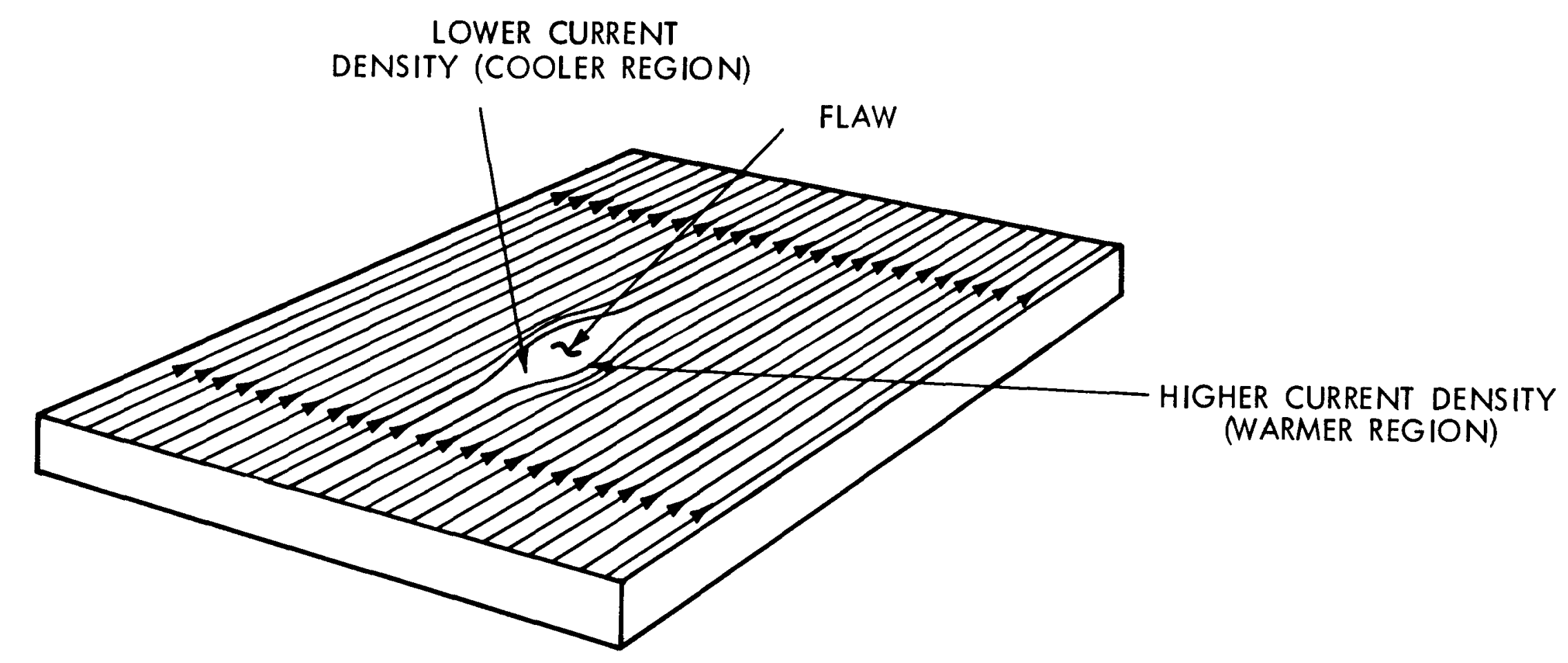

HEDL 7507-84.3

FIGURE 2. Electric Current and Surface Heating Near a Surface Flaw. 
However, the problem was too complex for direct application of heat transfer codes available on the local central computer. Modification and adaptation of these codes would have been too costly for the modest scope of the present work. For this reason, no computer analys is of temperature distributions was performed. Instead, a simple experimental evaluation, coupled with analytical computations to determine the desirable heating pulse-length range, was performed. The pulse-length computations made it possible to design the equipment and experiments. Computation of the heating pulse-length (shown in Appendix A) was based upon the time required for heat to diffuse from an instantaneous point source and raise the temperature $0.1 \mathrm{~cm}(0.039 \mathrm{in}$.) away from the point to about 50 percent of the value at the point. Hence, the pulse length can be thought of as the time required for heat, instantaneously deposited in an infinitesimal volume, to diffuse and become a hot spot of $0.1 \mathrm{~cm}$ radius. This radius was chosen to correspond to the approximate minimum size of picture element resolved by the infrared scanner used in the experiments.

\section{EXPERIMENTAL APPARATUS}

The experimental electro-thermal system assembled for this work is shown in Figure 3. Test specimens were clamped into a copper bus-bar contact assembly shown mounted on the impedance matching transformer centered in the background of Figure 3. A closeup of the bus-bar contact assembly is shown, together with a test specimen in Figure 4. Each end of the test specimen was clamped between two copper contact bars, as can be seen in the figure. A current path 2 inches $(5.08 \mathrm{~cm})$ long through the test specimen was used in all cases. The symmetrical mechanical arrangement made it possible to mount the test specimen with its notch toward the infrared scanner (hereafter called the near side), or with the notch away from the scanner (far side). Hence, both surface defects and subsurface defects were represented by the same test plates by simply turning them over in the contact assembly. The effect of applying the electric current through contacts only on the near side of the specimen was created by insulating the far side of the specimen from its contacts. 


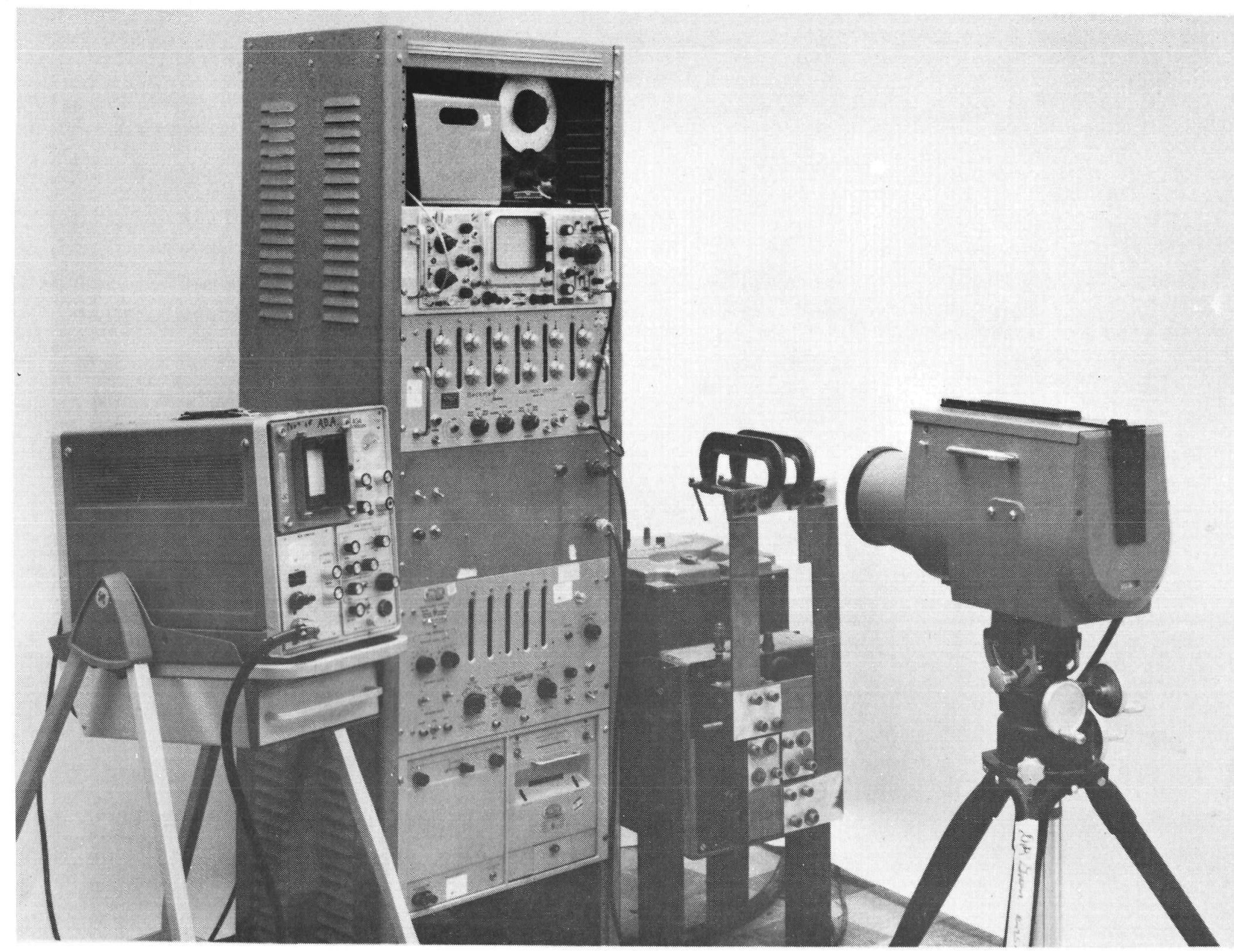

FIGURE 3. Experimental Electro-Thermal System for Stainless Steel Plate Specimens. 


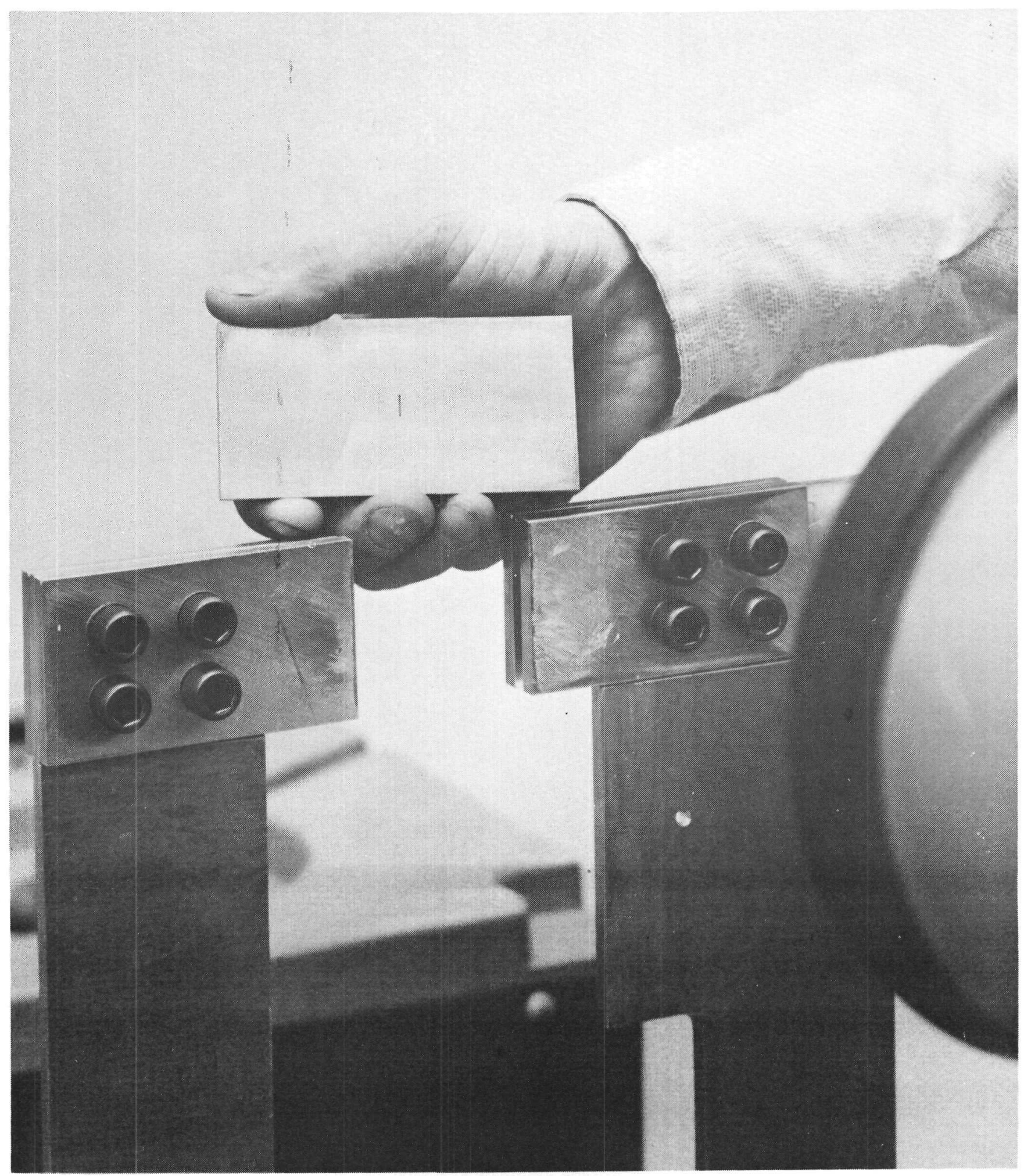

FIGURE 4. Stainless Steel Plate Specimen and Output Contact Bars of the Electro-Thermal System. 
The impedance matching transformer was capable of 100 kva output at 6 vac with an input of $440 \mathrm{vac}$. Voltage supplied to the transformer was controlled with a stack of variable transformers in tandem, together with a 100 kva contactor to switch the input power on and off. Although somewhat more cumbersome than a silicon-controlled rectifier system, the components for this power control system were readily available onsite, and were satisfactory for producing the necessary pulse lengths and power amplitudes.

Closure time of the contactor was controlled with a dual preset counter which was driven with a $10 \mathrm{kHz}$ clock oscillator input. The contactor was arranged to close when the first preset count was reached, and open when the second preset was reached. In this way, an accurate power pulse length was generated. Variations in response of the contactor were not great enough to cause appreciable errors in the closure times used.

An infrared thermal scanning camera, shown in the right foreground of Figure 3 , and its video display console shown on the left, mapped the test specimen's surface temperature at 1/16 second intervals during each test. The thermal map, imaged on the video display, was photographed with an electronically triggered camera (not shown in Figure 3 ) at the end of the power pulse supplied to the test specimen. No attempt was made to synchronize the photographic camera with the framing rate of the infrared scanning camera, and overlapping of successive rasters was troublesome. This sometimes caused an upper or lower portion of the photographed video image to appear brighter than the rest. Although this meant that some photographs had to be repeated, good enough results for evaluation of the method were quickly obtained in most cases.

\section{TEST SPECIMENS}

Thirteen Type 304 stainless steel plates $5 \mathrm{~cm} \times 10 \mathrm{~cm} \times 0.5 \mathrm{~cm}(2 \times 4$ $x 0.2$ inch) each containing one electric discharge machined (EDM) notch, as shown in Figure 5 , were used in this evaluation. The notches were thin enough $(0.013 \mathrm{~cm}, 0.005$ inch) that they were electrically and thermally representative of thin planar defects such as lack of fusion and cracks. 


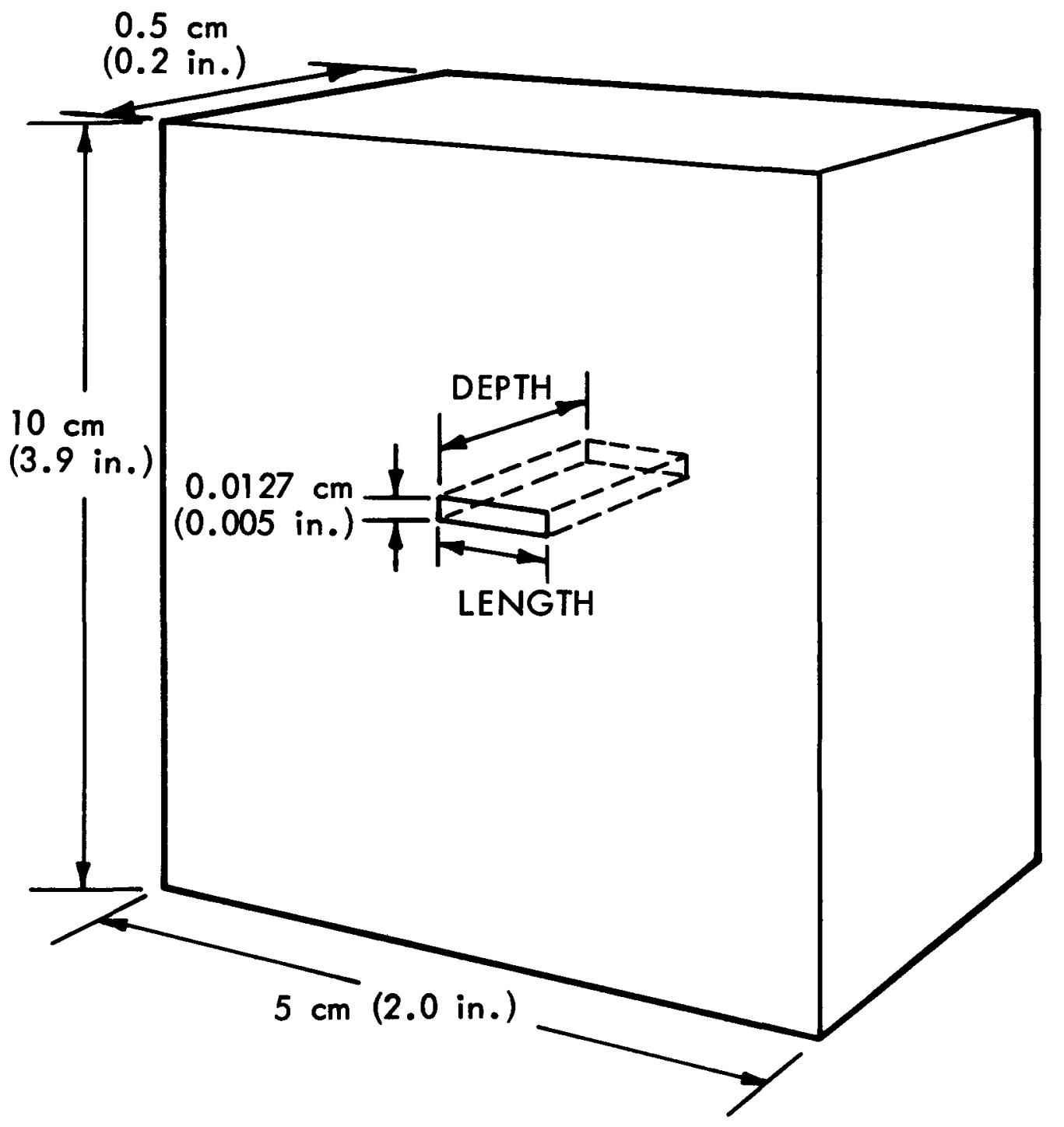

HEDL 7507-84.1

FIGURE 5. Stainless Steel Plate Specimen Containing Electric Discharge Machined Notch. 
However, practical limitations prevented making the notches thin enough that the infrared radiation cavity effect was avoided during infrared scanning. Hence, although the thermal distribution around the artificial notches at the surface was representative of that which would be produced by an equivalent thin crack, the apparent temperature within each notch, as mapped by the infrared scanner, was higher due to the higher effective infrared emittance of the notch. This unavoidable consequence of using artificial notches is easily discounted from the results, however, since the notch locations are known. Sizes of the notches are shown in Table I. Due to budget limitations, specimen plates containing notches with some of the possible length-depth combinations in the table could not be prepared. These are shown as blanks in the table.

TABLE I

NOTCH SIZES*

Notch Depth

$\mathrm{cm}$ (in.)

\begin{tabular}{cc} 
& Notc \\
\hline 0.08 & 0.16 \\
$(0.03)$ & $(0.06$ \\
\hline
\end{tabular}

$0.08(0.03)$

$$
x
$$

$\mathrm{X}$

$x$

$x$

$x$

$0.16(0.06)$
$0.32(0.12)$

*Width of all notches $0.013 \mathrm{~cm}(0.005 \mathrm{in.})$

\section{EXPERIMENTAL PROCEDURE AND RESULTS}

Three sets of experiments were run to evaluate the electro-thermal method's sensitivity to surface and subsurface defects in stainless steel. Each set of experiments was run using a different combination of contact and notch arrangements, as shown in Figure 6. Symmetrical electrical contact represents the practical case where the contacts are on one or both surfaces and are far enough apart that the current is uniformly distributed through the test specimen's volume in the scanned region. Contact at only the near 


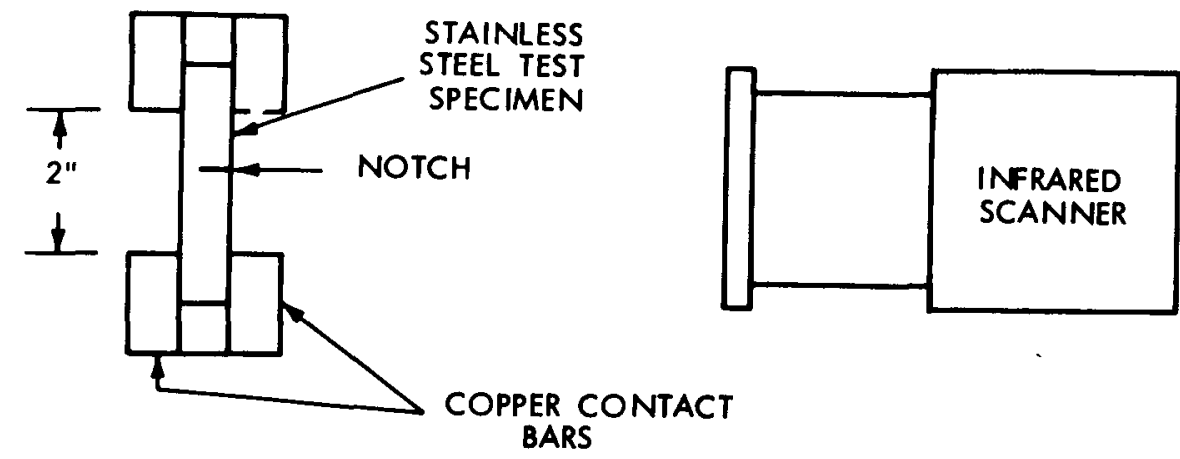

A. SYMMETRICAL ELECTRICAL CONTACT. NOTCH ON NEAR SIDE

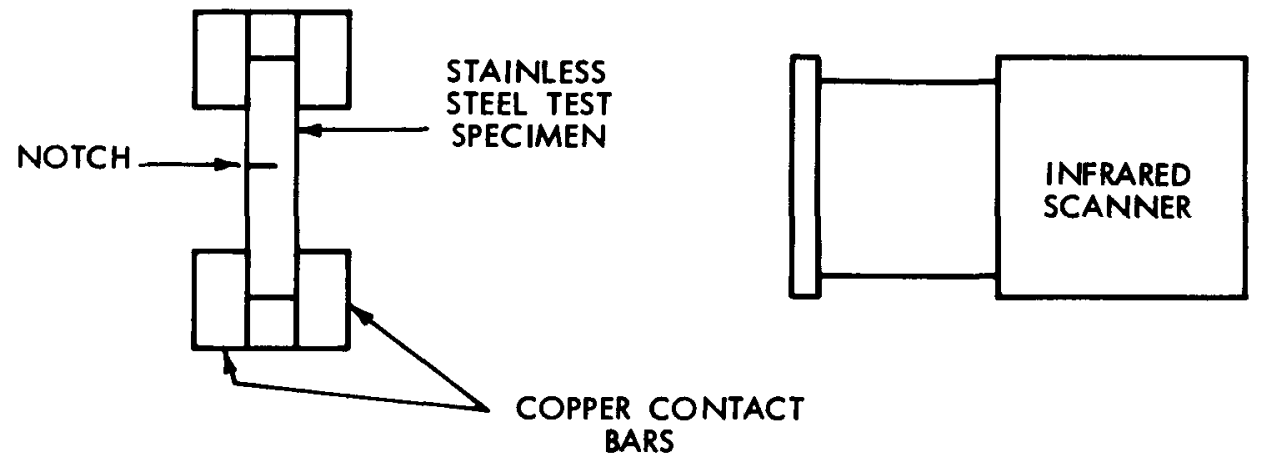

B. SYMMETRICAL ELECTRICAL CONTACT. NOTCH ON FAR SIDE

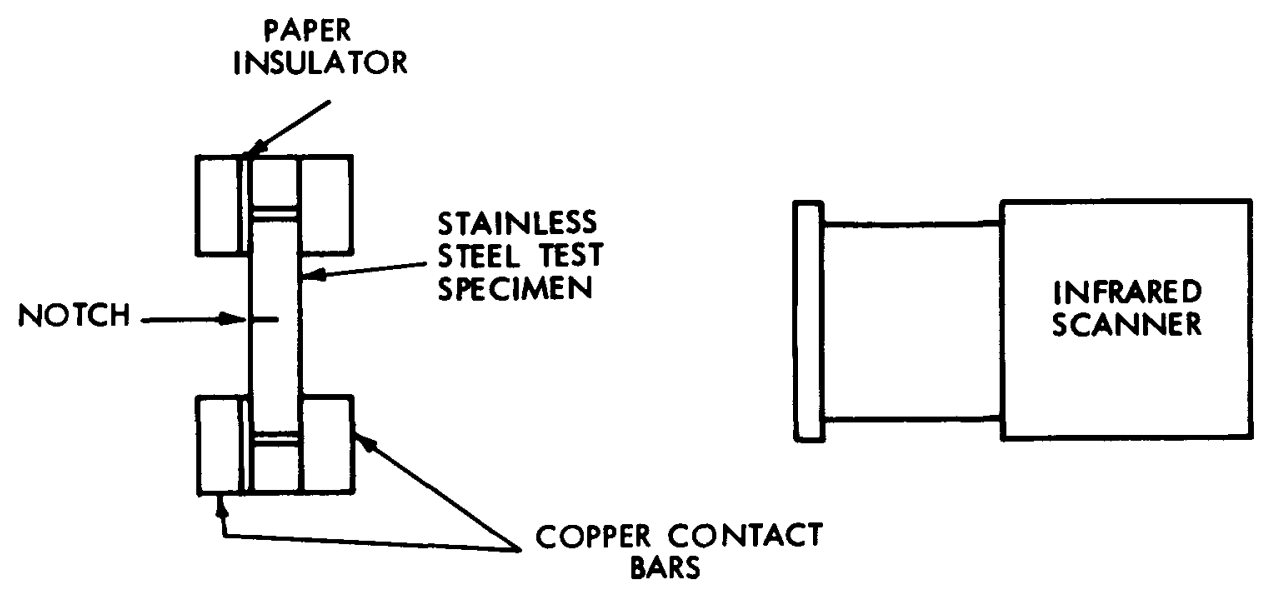

C. ELECTRICAL CONTACT ON NEAR SURFACE. NOTCH ON FAR SIDE. HEDL 7507-84.4

FIGURE 6. Three Experimental Arrangements Used in the Sensitivity Evaluations. 
surface simulates the practical case of a closed test specimen such as a pipe where the contacts are close together and can only be placed on the outside. A notch on the near surface represents a planar flaw such as a crack or lack of fusion that intersects the surface viewed by the scanner. Far surface notches can be considered to represent flaws on the inside surface of a test object, such as a pipe, which must be viewed from the outside. They also represent flaws centered inside the volume of a test object when symmetrical electrical contact is used. In the latter case, the flaw depth size and the electrical current applied to the test object would have to be considered twice as great in the actual test object than in the representative specimen plate to give the same surface temperature pattern.

Surface emittance differences from one region to another in the test specimens were not great enough to mask the temperature distribution around the notches in most cases. Hence, no attempt was made to eliminate emittance effects in most of the experiments since the use of coatings or complicated emittance independent methods was considered less desirable in a practical test. However, a coating was used in a few of the experiments and was found to increase the test sensitivity somewhat, as shown later.

Electrical current that could be supplied to the test specimens was 1 imited by the contact between the contact bars and specimen. The system had to be operated at 75 percent or less of its full current capacity. High spots on the bars and specimen caused uneven contact and hot spots that resulted in pitting when the current was set too high.

Results of the first series of experiments are summarized in Table II. These experiments used the near side surface defect and symmetrical heating arrangement pictured in Figure 6A. As mentioned earlier, the cavity effect (indicated by a "C" in Table II) is not a satisfactory means of detecting extremely thin planar surface defects in practical specimens. The minute thickness of the defect would be too far below the resolution of the infrared scanner. On the other hand, even extremely thin defects can be detected by the temperature distribution effect. As can be seen in Table II, notches down to $0.08 \mathrm{~cm}(0.03$ inch) depth and $0.32 \mathrm{~cm}(0.12$ inch) long were detected using the surface temperature distribution effect (indicated by a "D"). 
TABLE II

\section{SENSITIVITY TO NEAR-SIDE SURFACE DEFECTS* IN SPECIMENS WITH SYMMETRIC CURRENT APPLICATIONS}

\section{Notch Depth $\mathrm{cm}$ (in.)}

$0.08(0.03)$

$0.16(0.06)$

$0.32(0.12)$

\begin{tabular}{llccc}
\multicolumn{5}{c}{ Notch Length $-\mathrm{cm}$ (in.) } \\
\hline 0.08 & 0.16 & 0.32 & 0.64 & 1.28 \\
$(0.03)$ & $(0.06)$ & $(0.12)$ & $(0.25)$ & $(0.50)$
\end{tabular}

$$
\text { C }
$$

C

D

D

$\begin{array}{lllll}C & D & D & D\end{array}$

\footnotetext{
*D $=$ detectable from surface temperature pattern.

$C=$ detectable only through cavity effect.

Blank = not run.
}

Figure 7 shows typical infrared thermal maps from the Figure 6A arrangement (near surface notch, symmetrical current) for three different notch sizes. Electrical current flow during the experiments was horizontal relative to the thermal maps in Figure 7 . The dark regions upstream and downstream from the bright, cavity effect line centered over the notches are low temperature zones due to lower local currents resulting from the higher impedance of the notch. The bright flares visible at the ends of the largest notch are high temperature zones resulting from high local currents that are caused by crowding as the current was forced to flow around the ends of the notch. The bright flares at the ends of the small notches are not as prominent as the upstream and downstream dark regions.

The effect of coating the test specimen to eliminate emittance variations was determined by repeating some of the first series experiments after coating the specimens with flat black lacquer. The results of these experiments are shown in Table III. Figure 8 shows the infrared thermal maps from two of the experiments. Note that the high emittance cavity of the notch no longer appears as a bright line, but has an emittance more nearly equal to that of the coated specimen and therefore has nearly the same brightness as 

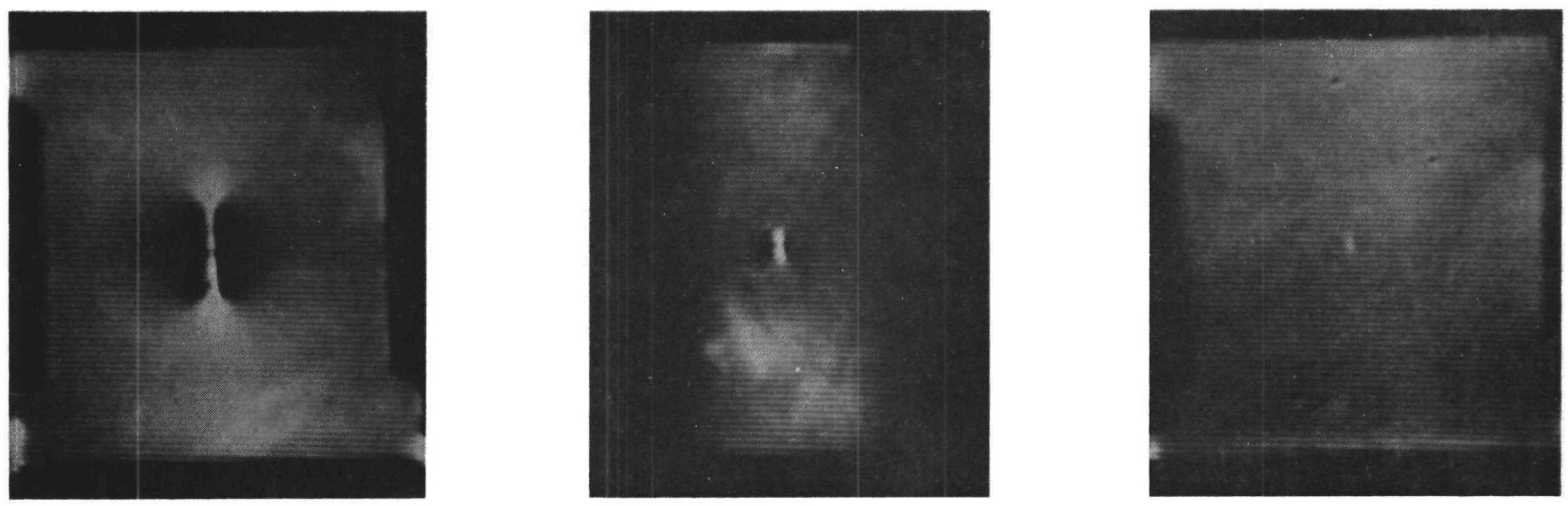

Left: Notch $1.28 \mathrm{~cm}(0.5 \mathrm{in})$ long $\times 0.32 \mathrm{~cm} .(0.12 \mathrm{in})$ deep. Current density $69 \mathrm{amp} / \mathrm{mm}^{2}$ for $0.1 \mathrm{sec}$.

Center: Notch $0.32 \mathrm{~cm}(0.12$ in) long $\times 0.16 \mathrm{~cm}(0.06$ in) deep. Current density $69 \mathrm{amp} / \mathrm{mm}^{2}$ for $0.05 \mathrm{sec}$.

Right: Notch $0.16 \mathrm{~cm}(0.06 \mathrm{in})$ long $\times 0.16 \mathrm{~cm}(0.06 \mathrm{in})$ deep. Current density $49 \mathrm{amp} / \mathrm{mm}^{2}$ for $0.1 \mathrm{sec}$.

FIGURE 7. Electro-Thermal Indications of $0.013 \mathrm{~cm}(0.005$ in.) wide Notches in $0.5 \mathrm{~cm}(0.2$ in.) thick $\times 5 \mathrm{~cm}$

(2 in.) wide Stainless Steel Plate. 
the adjacent metal. Note also the improvement in sensitivity when a flat black coating was applied to increase the emittance and make it more uniform. (Compare results of the uncoated case for the $0.16 \mathrm{~cm} \times 0.16 \mathrm{~cm}$ notch in Figure 7 to results of the coated case for the smaller $0.16 \mathrm{~cm} \times 0.08 \mathrm{~cm}$ notch in Figure 8.) Development of a technique eliminating emittance effects by a method not using a coating would be desirable.

TABLE III

SENSITIVITY TO NEAR-SIDE SURFACE DEFECTS IN FLAT BLACK COATED SPECIMENS WITH SYMMETRIC CURRENT APPLICATION

Notch Depth

$\mathrm{cm}$ (in.)

$0.08(0.03)$

$0.16(0.06)$

$0.32(0.12)$

\begin{tabular}{ccccc}
\multicolumn{5}{c}{ Notch Length $-\mathrm{cm}$ (in.) } \\
\hline 0.08 & 0.16 & 0.32 & 0.64 & 1.28 \\
$(0.03)$ & $(0.06)$ & $(0.12)$ & $(0.25)$ & $(0.50)$ \\
\hline
\end{tabular}

D

$D$

A second series of experiments used the experimental arrangement pictured in Figure 6B (symmetric electrical contact, notch placed on far side). This case represents both internal surface and volumetric defects. Table IV summarizes the sensitivity for this arrangement. Detection of notches down to $0.16 \mathrm{~cm}(0.06 \mathrm{in.})$ long $\times 0.32 \mathrm{~cm}(0.12 \mathrm{in.})$ deep and $0.64 \mathrm{~cm}(0.24 \mathrm{in.})$ long $x 0.16 \mathrm{~cm}$ (0.06 in.) deep was firmly demonstrated in this case. Note that the notch depth is defined as a dimension of the notch itself (refer to Figure 5) and in this case must be subtracted from the $0.5 \mathrm{~cm}(0.2 \mathrm{in.})$ plate thickness to determine how far the notch is submerged under the near surface. Figure 9 shows typical infrared thermal maps for three notch sizes in this series.

A third series of experiments used the arrangement pictured in Figure $6 \mathrm{C}$ (near side electrical contact, far side notch). This arrangement is probably the closest to the one that would be used in most practical applications. 

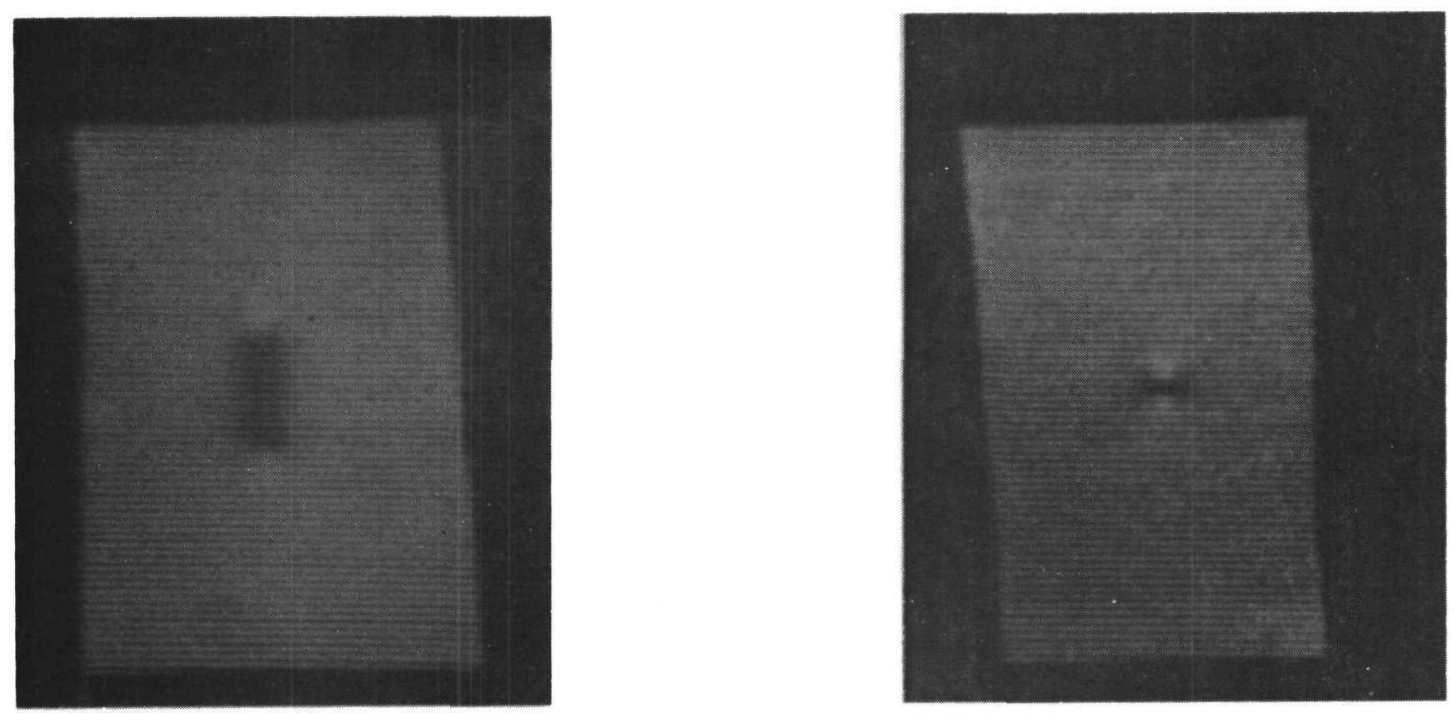

Left: Notch $1.28 \mathrm{~cm}(0.5 \mathrm{in})$ long $\times 0.16 \mathrm{~cm}$ ( 0.06 in) deep. Current density approximately $40 \mathrm{amp} / \mathrm{mm}^{2}$ for $0.1 \mathrm{sec}$.

Right: Notch $0.16 \mathrm{~cm}$ (0.06 in) 1ong $\times 0.08 \mathrm{~cm}(0.03$ in) deep. Current density approximately $49 \mathrm{amp} / \mathrm{mm}^{2}$ for $0.1 \mathrm{sec}$.

FIGURE 8. Electro-Thermal Indications of $0.013 \mathrm{~cm}(0.005 \mathrm{in.})$ wide Notches in the Near Side of Flat Black Coated Stainless Steel Plates $0.5 \mathrm{~cm}(0.2 \mathrm{in.})$ thick $x$ $5 \mathrm{~cm}$ (2 in.) wide. Electric current applied symmetrically. 

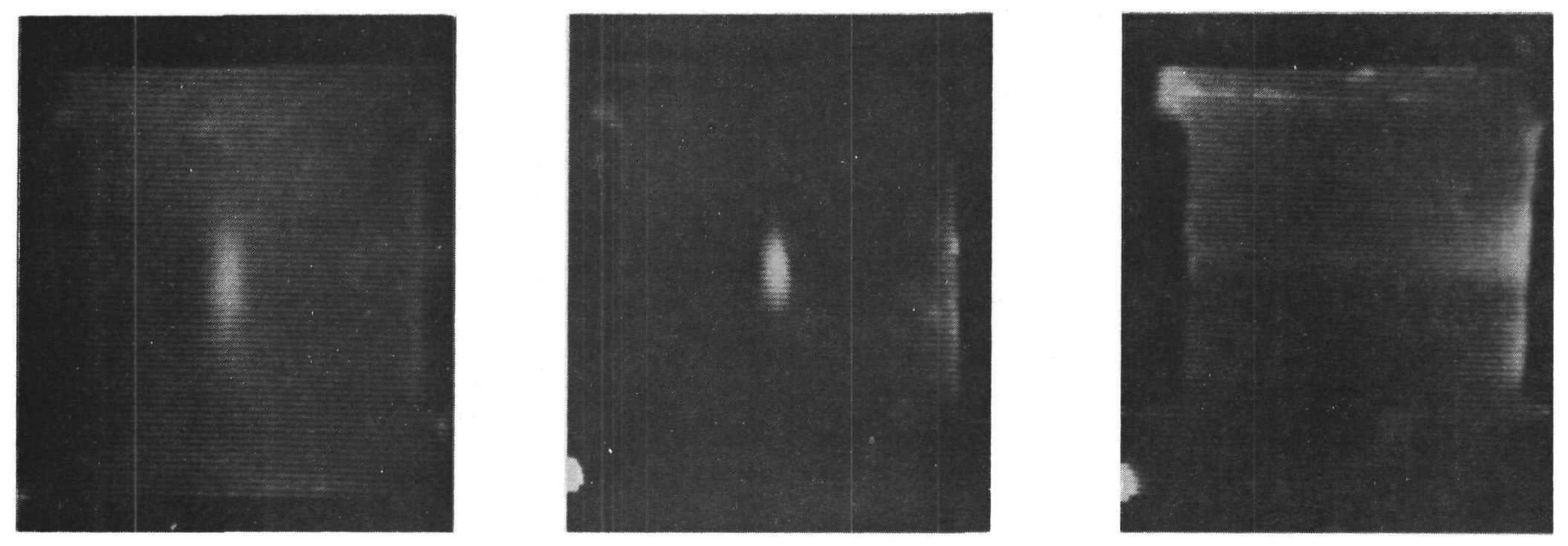

Left: Far-side notch $1.28 \mathrm{~cm}\left(0.5\right.$ in) long $\times 0.32 \mathrm{~cm}_{2}(0.12$ in) deep. Current density approximately $49 \mathrm{amp} / \mathrm{mm}^{2}$ for $0.1 \mathrm{sec}$.

Center: Far-side notch $0.64 \mathrm{~cm}(0.25$ in) long $\times 0.32 \mathrm{~cm}(0.12 \mathrm{in})$ deep. Current density approximately $69 \mathrm{amp} / \mathrm{mm}^{2}$ for $0.1 \mathrm{sec}$.

Right: Far-side notch $1.28 \mathrm{~cm}(0.5$ in) long $\times 0.08 \mathrm{~cm}(0.03 \mathrm{in})$ deep. Current density approximately $69 \mathrm{amp} / \mathrm{mm}^{2}$ for $0.1 \mathrm{sec}$.

FIGURE 9. Electro-Thermal Indications of $0.013 \mathrm{~cm}(0.005 \mathrm{in.})$ wide notches in the Far Side of $0.5 \mathrm{~cm}(0.02 \mathrm{in.})$ thick $\times 5 \mathrm{~cm}$ (2 in.) wide Stainless Steel Plates. Electric current applied symmetrically. 
TABLE IV

SENSITIVITY TO FAR-SIDE SURFACE DEFECTS IN SPECIMENS WITH SYMMETRIC CURRENT APPLICATION*

Notch Depth

$\mathrm{cm}$ (in.)

$0.08(0.03)$

$0.16(0.06)$

$0.32(0.12)$

\begin{tabular}{ccccc}
\multicolumn{5}{c}{ Notch Length $-\mathrm{cm}$ (in.) } \\
\hline 0.08 & 0.16 & 0.32 & 0.64 & 1.28 \\
$(0.03)$ & $(0.06)$ & $(0.12)$ & $(0.25)$ & $(0.50)$ \\
\hline
\end{tabular}

Q

N D D

D D D

$\star_{D}=$ detectable from surface temperature pattern.

$Q=$ detection from surface temperature pattern questionable.

$N=$ not detected.

Blank = not run.

It represents external detection of a flaw on the inside surface of a closed assembly, such as a pipe. It also represents detection of a flaw centered in a volume such as a pipe wall or a bar, as explained earlier. Results of these experiments are summarized in Table $V$. With this arrangement, and in the present stage of development, the electro-thermal method is capable of detecting far surface defects down to $0.08 \mathrm{~cm}(0.03 \mathrm{in}$.) deep $\times 1.28 \mathrm{~cm}$ (0.50 in.) long and $0.32 \mathrm{~cm}(0.12 \mathrm{in.})$ deep $\times 0.32 \mathrm{~cm}(0.12 \mathrm{in.})$ long. The corresponding minimum sized detectable volumetric defects (centered in the volume of a plate twice as thick) would be approximately $0.16 \mathrm{~cm}(0.06 \mathrm{in}$.) $\times 1.28 \mathrm{~cm}(0.50 \mathrm{in.})$ long and $0.64 \mathrm{~cm}(0.25 \mathrm{in.}) \times 0.64 \mathrm{~cm}(0.25 \mathrm{in.})$ long. As explained earlier, an electrical current approximately twice as great would be necessary in the volumetric case to maintain the same current density. The output thermal maps for this third series of experiments were similar to those for the second series (see Figure 9).

The results obtained during this study have shown that most prominent infrared (surface temperature) features of electro-thermal indications of notches are two adjacent dark (low temperature) regions associated with near side (surface) defects, and a single bright (high temperature) region associated with far side and subsurface defects. Qualitative interpretation of the results appears to be relatively straightforward. 
TABLE $V$

SENSITIVITY TO FAR-SIDE SURFACE DEFECTS IN SPECIMENS WITH NEAR-SIDE CURRENT APPLICATION*

Notch Depth

cm (in.)

$0.08(0.03)$

$0.16(0.06)$

$0.32(0.12)$

\begin{tabular}{ccccc}
\multicolumn{5}{c}{ Notch Length $-\mathrm{cm}($ in. $)$} \\
\hline 0.08 & 0.16 & 0.32 & 0.64 & 1.28 \\
$(0.03)$ & $(0.06)$ & $(0.12)$ & $(0.25)$ & $(0.50)$
\end{tabular}

$\mathrm{N}$

D

N Q D

N

D

D

D

${ }^{*} D=$ detectable from surface temperature pattern.

$Q=$ detection from surface temperature pattern questionable.

$\mathrm{N}=$ not detected.

$\mathrm{Blank}=$ not run.

\section{ACKNOWLEDGMENTS}

It is a pleasure to acknowledge the helpful technical suggestions and the work of J. C. Spanner, Manager, NDT Engineering, to establish the program under which this work was done. The assistance of R. G. Chafin in conducting some of the experiments and the machine work of $0 . K$. Selle in fabricating the specimens is also gratefully acknowledged.

\section{REFERENCE}

1. H. S. Carslaw and J. C. Jaeger, Conduction of Heat in Solids, 2nd Ed., Oxford University Press, 1954. 


\section{APPENDIX A \\ TEMPERATURE VERSUS TIME AROUND AN INSTANTANEOUS \\ POINT HEAT SOURCE}

The temperature $\left(\mathrm{C}^{\circ}\right)$ around an instantaneous point source of heat is given by (1)

$$
\left.v=\frac{H}{\rho C\left(4 \pi_{\alpha} t\right)^{3 / 2}} \exp -\left[x-x^{\prime}\right)^{2}+\left(y-y^{\prime}\right)^{2}+\left(z-z^{\prime}\right)^{2}\right] / 4 \alpha t
$$

where $H$ is the heat (cal) deposited at point $x^{\prime}, y^{\prime}, z^{\prime}$ at time, $t=0$, $\alpha$ is thermal diffusivity, $\rho$ is density $\left(\mathrm{g} / \mathrm{cm}^{3}\right), C$ is heat capacity $\left(\mathrm{cal} / \mathrm{g}^{\circ} \mathrm{C}\right)$, and $x, y$ and $z$ are the cartesian coordinates of the general point at which the temperature, $v$, is to be computed. Designating the heat deposition point as the origin, and reducing the equation to polar coordinates,

$$
v=\frac{H}{\rho C(4 \pi \alpha, t)^{3 / 2}} \exp \left[-r^{2} / 4 \alpha t\right],
$$

where $r$ is the radius from the origin to the general point. This equation is, of course, only useful for $t \neq 0$. The ratio of temperature at a general point to that at the origin is given by

$$
\begin{aligned}
R & =\exp \left[-r^{2} / 4 \alpha t\right] / \exp [0] \\
& =\exp \left[-r^{2} / 4 \alpha t\right] .
\end{aligned}
$$

For type 304 stainless steel, this becomes

$$
R=\exp \left[-6.25 r^{2} / t\right] \text {. }
$$

If we assume $t=0.1 \mathrm{sec}$ and $r=0.1 \mathrm{~cm}$, we obtain

$$
R=0.54
$$

as the ratio of temperature on a $0.1 \mathrm{~cm}$ radius circle to the temperature at its center where the heat was originally deposited. Hence, $0.1 \mathrm{sec}$ is the time required for a point disturbance in a thermal field to diffuse and become a spot disturbance with about a $1 \mathrm{~mm}$ radius. A much shorter time than this requires higher instantaneous power inputs and increases the risk of 
burning pits under the electrical contacts. A much longer time gives a more diffuse thermal map and would not use the full resolution of the infrared scanning camera which is capable of resolving features separated by about 1 to $2 \mathrm{~mm}$, depending upon the temperature differences and distribution. 
DISTRIBUTION
UC-79
(186)
UC-79i (20)
UC-79k (38)
UC-79m (25)
ERDA-RL (3)
A. G. Fremling
R. M. Poteat
A. R. DeGrazia

FFTF/P0

(1)

R. L. Ferguson

ERDA-HQ (2)

Director

HEDL (59)

J. M. Atwood

C. A. Burgess

R. L. Brown

C. M. Cox

G. E. Cully

T. T. Claudson

A. W. DeMerschman

C. K. Day

R. E. Dahl

E. A. Evans

T. W. Evans

D. C. Frick

D. R. Green

(2)

W. H. Gray

B. R. Hayward

J. A. Hassberger

J. E. Hanson

(2)

Central Records and Files (20)

Publications Services

(2)
J. J. Holmes

C. N. Jackson

F. J. Leitz

G. A. Last

L. D. Muhlestein

S. J. Mech

E. A. Proudfoot

L. A. Pember

R. 0 . Petersen

L. H. Rice

W. E. Roake

A. L. Smith

J. C. Spanner

W. F. Sheely

R. L. Trantow

J. M. Yatabe 